\title{
Modulating Crystallization in Semitransparent Perovskite Films Using Submicrometer Spongelike Polymer Colloid Particles to Improve Solar Cell Performance
} DOI:

10.1021/acsaem.9b01162

Link to publication record in Manchester Research Explorer

Citation for published version (APA):

Saunders, B. (2019). Modulating Crystallization in Semitransparent Perovskite Films Using Submicrometer Spongelike Polymer Colloid Particles to Improve Solar Cell Performance. ACS Applied Energy Materials. https://doi.org/10.1021/acsaem.9b01162

Published in:

ACS Applied Energy Materials

\section{Citing this paper}

Please note that where the full-text provided on Manchester Research Explorer is the Author Accepted Manuscript or Proof version this may differ from the final Published version. If citing, it is advised that you check and use the publisher's definitive version.

\section{General rights}

Copyright and moral rights for the publications made accessible in the Research Explorer are retained by the authors and/or other copyright owners and it is a condition of accessing publications that users recognise and abide by the legal requirements associated with these rights.

\section{Takedown policy}

If you believe that this document breaches copyright please refer to the University of Manchester's Takedown Procedures [http://man.ac.uk/04Y6Bo] or contact uml.scholarlycommunications@manchester.ac.uk providing relevant details, so we can investigate your claim.

\section{OPEN ACCESS}




\section{Modulating crystallization in semi-transparent perovskite}

\section{films using sub-micrometer sponge-like polymer colloid}

\section{particles to improve solar cell performance}

Chotiros Dokkhan ${ }^{a}$, Muhamad Z. Mokhtar ${ }^{a}$, Chun-Ren Ke ${ }^{b}$, Alex S. Walton ${ }^{b}$, Qian Chen $^{a}$,

Nigel W. Hodson ${ }^{c}$, Qing $\operatorname{Lian}^{a}$ and Brian R. Saunders ${ }^{a} *$

${ }^{a}$ School of Materials, University of Manchester, MSS Tower, Manchester, M13 9PL, U.K. ${ }^{b}$ Photon Science Institute, University of Manchester, Alan Turing Building, Oxford Rd, Manchester M13 9PL, U.K. ${ }^{c}$ BioAFM Facility, Faculty of Biology, Medicine and Health, Stopford Building, University of Manchester, Oxford Road, Manchester, M13 9PT, U.K.

Key words: Perovskite solar cell, semitransparent, microgel, crystallization, average visible transmittance

\section{Corresponding author}

Brian R. Saunders: brian.saunders@manchester.ac.uk 


\section{ABSTRACT}

Semi-transparent perovskite solar cells (PSCs) have excellent potential for solar window applications. A major challenge exists, however, in achieving uniform coverage for thin perovskite films. Unfortunately, uncontrolled pinhole formation is a common problem for such films that obstructs development, especially for large area devices. In this study we used very small (submicrometer) swellable polymer colloid particles (microgels) as additives to prepare uniform thin $\mathrm{CH}_{3} \mathrm{NH}_{3} \mathrm{PbI}_{3}$ (MAPI) perovskite films. Microgels (MGs) are good film-formers and promoted formation of semi-transparent (ST) perovskite films with improved coverage. The MGs act as colloidal sponges and delayed release of perovskite precursors, thereby delaying perovskite crystallization. The ST films prepared using MGs had fewer pinholes compared to the MG-free control films. X-ray photoelectron spectroscopy showed evidence of Pb coordination by the MGs and they were shown to passivate MAPI. Remarkably, the sub-micrometer MGs used in this study decreased light scattering for the ST films. Planar devices constructed using a $10 \mathrm{~nm}$ ST film with an average visible transmittance of $46.8 \%$ gave an average power conversion efficiency (PCE) of $7.69 \%$ which compares favourably to literature values. The average PCE increased to $9.62 \%$ upon inclusion of a thin meso- $\mathrm{TiO}_{2}$ layer. These PCE values are significantly higher than that achieved for the MG-free ST control (4.93\%). The MGs and approaches used here are scalable and should apply to other ST perovskite films, solar cells and potentially to tandem devices.

\section{INTRODUCTION}

In only a decade the power conversion efficiency (PCE) for perovskite solar cells (PSCs) has increased dramatically from $3.8 \%^{1}$ to $24.2 \%^{2}$ and further PCE increases are anticipated. Simultaneously, the understanding of the charge transport mechanisms has greatly improved ${ }^{3-5}$. Hence, the excitement surrounding these remarkable photoactive materials ${ }^{6-9}$ shows no sign of abating $^{10-19}$ with many factors favouring their eventual commercialisation. These include potential for scale up and their likely competitive production $\operatorname{cost}^{20-23}$. PSCs are also attractive because they are defect tolerant ${ }^{24}$ which has enabled a wide range of additives to be used whilst still achieving 
viable (or even improved) PCEs $^{13}$. These additives are not only limited to small molecules ${ }^{25}$ but have included linear polymers such as poly(4-vinylpyridine $)^{26}$, poly(vinylpyrrolidone $)^{27}$ and poly(2ethyl-2-oxazoline $)^{28}$. Recently, we reported PSCs containing high proportions of micrometer-sized swellable microgel (MG) particles. (MGs are sponge-like polymer particles that swell in a good solvent $^{29}$.) Remarkably, inclusion of these relatively large colloidal additives gave viable devices ${ }^{30}$. Additives may provide passivation for defects ${ }^{25}$ and also delay crystallization and increase grain size $^{31}$. Whilst colloidal additives have been used to prepare PSCs ${ }^{30,32}$, they are still in their infancy of being explored within the perovskite photoactive layer, especially in terms of additive-perovskite interactions and their roles in controlling perovskite crystallization. In this study we use small submicrometer MGs to prepare semi-transparent (ST) perovskite films and PSCs.

Whilst many PSC studies focus on devices with relatively thick perovskite layers (> $100 \mathrm{~nm})$, much thinner ST PSCs are attracting strong interest ${ }^{33-36}$ because of their potential for solar window use. Houses and offices account for $75 \%$ of the electricity use in the United States ${ }^{37}$. Hence, ST solar windows offer great potential to reduce the carbon footprint of buildings. In a seminal study, Snaith et al. reported neutral color ST PSCs prepared with microstructured perovskite films ${ }^{35}$. Because ST PSCs have a target application of power windows, aesthetic requirements are important. The minimum average visible transmittance (AVT) should be $25 \%$ for such applications ${ }^{38}$. Unfortunately, the dual goals of high AVT and PCE require compromise because they show a negative correlation ${ }^{39}$. Whilst decreasing the perovskite layer thickness has been widely used to increase the AVT, retaining a uniform pinhole-free morphology is challenging. This problem has led to the addition of linear polymer additives ${ }^{40}$. A problem with linear polymer additives is that it is difficult to identify and control their location within the resulting perovskite/polymer composites. A different approach explored in this study envisages using film-forming, swellable MGs to prepare ST perovskite films and PSCs. Whilst hydrophobic MGs were used to dilute the hole transport matrix of $\mathrm{PSCs}^{41}$, hydrophilic MGs that are directly mixed with the perovskite precursor solution have only been reported once ${ }^{30}$. The latter study used thick perovskite films and large MGs. 
Part of the attraction of ST PSCs is that they have the advantage of relatively facile modulation of the optical properties when compared to their silicon competitors, which is desirable for buildingintegrated and automotive-integrated photovoltaics ${ }^{42}$. Recent ST PSC research has included studies involving electrode engineering. For example, $\mathrm{Cu}$ and $\mathrm{Ni}$ top contact electrodes ${ }^{43}$ as well as $\mathrm{ZrAcac} / \mathrm{PEI} / \mathrm{Ag} / \mathrm{Ta}_{2} \mathrm{O}_{5}$ rear electrodes ${ }^{44}$ have been successfully used to fabricate devices with PCEs of $8.20 \%$ and $13.4 \%$, respectively. Perovskite composition control has been employed to prepare all inorganic $\mathrm{CsPbIBr}_{2}$ ST PSCs ${ }^{45}$ with a PCE of 5.59\%. Yuan et al. varied the I:Br ratio within $\mathrm{MAPbI}_{3-\mathrm{x}} \mathrm{Br}_{\mathrm{x}}$ to address the trade-off between PCE and $\mathrm{AVT}^{46}$. A unique approach to improve efficiency with high transmittance was used by Zhou et al. wherein the perovskite layer was doped with p-type semiconductor which removed the necessity for a hole transport layer ${ }^{47}$ and yielded devices with a PCE of $10.3 \%$. There have also been improvements in stability whereby ST PSCs with $4000 \mathrm{~h}$ of continuous operation have been reported ${ }^{48}$. ST PSCs have also been successfully prepared under ambient conditions ${ }^{49}$. However, there has been less attention given to the use of insulating polymer additives within ST PSCs.

Additives that interact with $\mathrm{Pb}$ have been added to perovskite precursor solutions to increase grain $\operatorname{size}^{50}$ by decreasing the nucleation rate ${ }^{51}$. These species have also included solvents which form $\mathrm{Pb}$ adducts and are removed by heating ${ }^{52}$. The crystallization rate may also be slowed by increasing solution viscosity ${ }^{23}$ and using higher boiling point co-solvents ${ }^{53}$. These approaches have mostly involved small molecules or polymers where the additive affects the whole solution uniformly. We postulated that MGs dispersed in perovskite precursor solution would gradually release precursor during spin-coating and delay film crystallization. This idea is investigated in the present study.

We recently showed that large (micrometer sized) MGs could be used to prepare disordered inverse opal perovskite films and PSCs ${ }^{30}$. The MGs used here comprise poly $(N$-vinyl formamide-co-2- $(N$ vinylformamido)ethyl ether) (PNVF-NVEE). They were selected because DMSO is a good solvent for the polymer and the perovskite precursors. (PNVF-NVEE is shown in Fig. 1A.) The MGs used 
earlier ${ }^{30}$ had a swollen diameter of $\sim 1.1 \mu \mathrm{m}$ and thick perovskite films resulted. We hypothesized that using much smaller (sub-micrometer) MGs would enable ST films to be prepared. There are five major differences for the present study when compared to our earlier work ${ }^{30}$. (1) The submicrometer PNVF-NVEE MGs used here are more than a factor of two smaller in diameter. This equates to a surface area increase of more than a factor of four. (2) Here, we study planar films without a meso- $\mathrm{TiO}_{2}$ layer. (3) We investigate ST perovskite films prepared using MGs for the first time. (4) We show that sub-micrometer MGs have major effects on perovskite morphology and passivation. (5) We demonstrate that MGs delay perovskite crystallization.
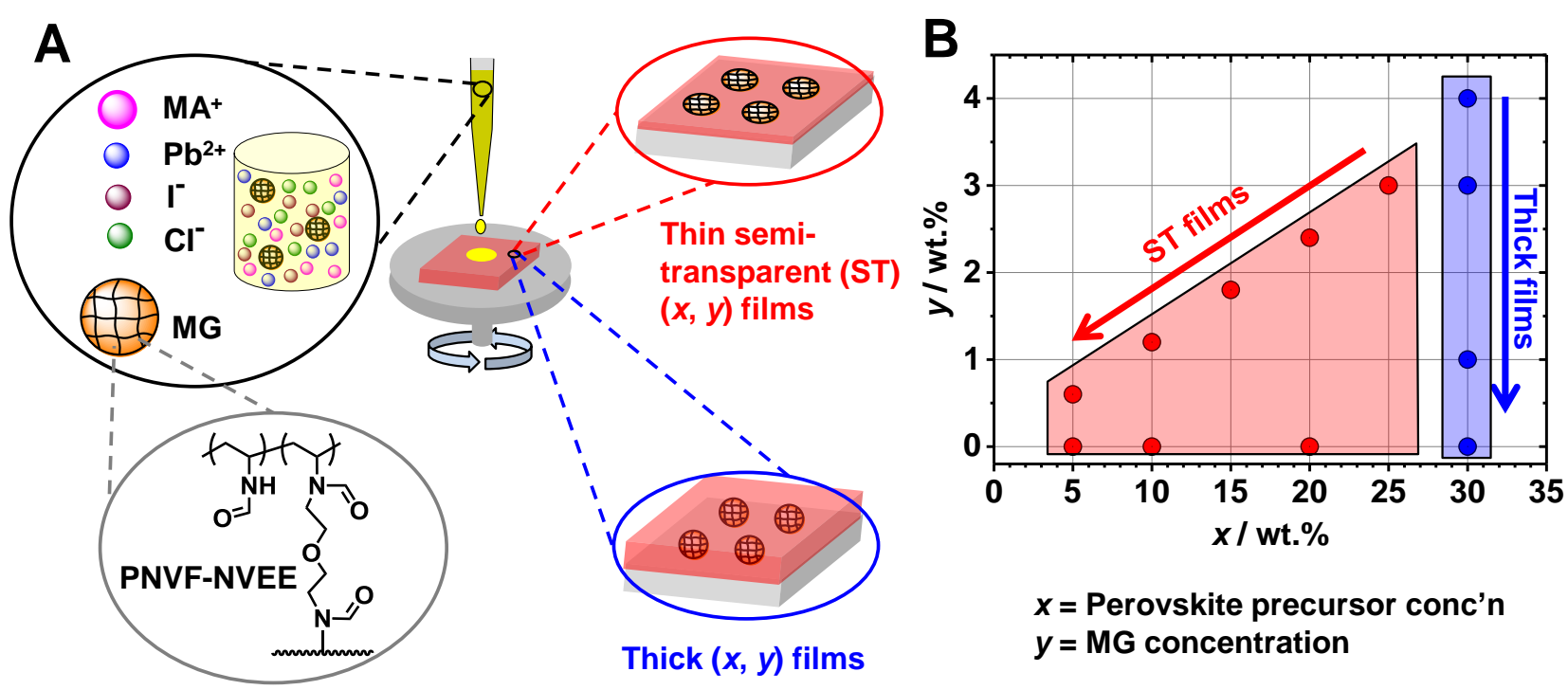

Figure 1. (A) Depiction of strategy used to obtain semi-transparent (ST) perovskite films using MG-modulated crystallization. The perovskite precursors and MGs are combined in a mixed solution and then spin-coated. PNVF-NVEE is $\operatorname{poly}(N$-vinyl formamide-co-2- $(N$ vinylformamido)ethyl ether). Note that the MG particles have a diameter of about three orders of magnitude larger than the ions. (B) Composition diagram for the systems investigated in this study.

In this study the perovskite/MG films are identified by the concentrations (wt.\%) of perovskite precursor $(x)$ and MG $(y)$ used for their preparation. For example, $(10,1.2)$ refers to a film prepared from solution containing $10 \%$ of perovskite precursor $\left(\mathrm{PbI}_{2}\right.$ and $\left.\mathrm{MAI}\right)$ and $1.2 \% \mathrm{MG}$. The compositions of all of the films studied are shown in Fig. 1B. We first begin by studying thick perovskite films and reveal for the first time, that MGs are located within the interior of perovskite 
films. The concentrations of perovskite precursor and MG are then systematically decreased to achieve ST films and we demonstrate that the MGs delay film formation. The MGs are shown to improve coverage of the thin films and, unexpectedly, to decrease light scattering. Furthermore, Xray photoelectron spectroscopy and photoluminescence (PL) provide evidence for an interaction between the MG and $\mathrm{Pb}$. Finally, we use the ST films with AVTs greater than $25 \%$ to construct PSCs. Devices prepared from the perovskite/MG film with an AVT of 46.8\% gave a PCE of 7.69\%, which was significantly higher than that for a MG-free system and compares favourably to literature values. The inclusion of a thin meso- $\mathrm{TiO}_{2}$ layer increased the PCE for the ST perovskite/MG system to $9.62 \%$ with only a small decrease in AVT. We believe that the sub-micrometer MGs used here for the first time have excellent potential for use in other ST PSCs.

\section{EXPERIMENTAL SECTION}

\section{Materials}

$N$-vinylformamide (NVF, 98\%), azoisobutyronitrile (AIBN, 98\%), potassium-tert-butoxide (95\%), bis(2-bromoethyl)ether (BBE, 95\%), dicyclohexyl-18-crown-6 (98\%), anhydrous tetrahydrofuran (THF, 99.9\%), and ethanol (EtOH, 99.9\%), poly(1-vinylpyrrolidone-co-vinyl acetate) (PVP-coPVA, $\left.M_{n} \sim 50,000 \mathrm{~g} / \mathrm{mol}\right)$, anhydrous sodium sulphate (100\%), chloroform (99.9\%), toluene (99.8\%), chlorobenzene (CBZ, 99.8\%), isopropanol (IPA, anhydrous, 99.5\%), 4-tert-butylpyridine (TBP, 96\%), lithium bistrifluoromethanesulfonimidate (LiTFSI, 99.95\%) and methylammonium chloride $\left(\mathrm{CH}_{3} \mathrm{NH}_{3} \mathrm{Cl}, \mathrm{MACl}\right)$ were all purchased from Aldrich and used as received. The $\mathrm{TiO}_{2}$ paste used in this study was Dyesol 18 NRT. Methylamine solution (33 wt.\% in absolute ethanol) and HI (57 wt.\%), titanium diisopropoxide bis(acetylacetonate) (TDB, 75 wt \% in IPA), $\mathrm{PbI}_{2}(98 \%)$, dimethyl sulfoxide (DMSO, 99.7\%) and N,N-dimethylformamide (DMF, 99.8\%) were also purchased from Aldrich and used as received. MAI was synthesized and purified using the method previously reported ${ }^{54}$. Spiro-MeOTAD $\quad\left(\right.$ Spiro, $\quad N^{2}, N^{2}, N^{2}, N^{2}{ }^{\prime}, N^{7}, N^{7}, N^{7^{\prime}}, N^{7^{\prime}}$-octakis(4methoxyphenyl) - 9,9' - spirobi [9H-fluorene] - 2,2',7,7'-tetramine, Fenglin Chemicals, 99.5\%) was 
also used as received. Water was of ultrahigh purity and de-ionized. NVEE was synthesized and characterized using the methods described previously ${ }^{55}$.

\section{Microgel synthesis}

New sub-micrometer PNVF-NVEE MGs were prepared by non-aqueous dispersion polymerization using a modification of the method described previously ${ }^{55}$. We discovered that by decreasing the total mass of monomers used by a factor of two compared to the earlier work the MG diameter decreased by a factor of two. Briefly, a mixture of NVF (3.00 g, $42.75 \mathrm{mmol})$, PVP-co-PVA (1.80 g) and NVEE (0.90 g, $4.16 \mathrm{mmol})$ were added to EtOH in a round bottomed flask equipped with overhead stirrer, nitrogen supply and a reflux condenser. The solution was heated to $70{ }^{\circ} \mathrm{C}$ and stirred vigorously. Then, AIBN (0.12 g, $0.73 \mathrm{mmol})$ in EtOH $(2.0 \mathrm{~mL})$ was added and the polymerization allowed to continue for $1 \mathrm{~h}$. The dispersion was filtered after cooling to $0{ }^{\circ} \mathrm{C}$ with a $50 \mu \mathrm{m}$ mesh filter and then purified by repeated centrifugation (three times) and re-dispersion in EtOH. To transfer the MGs from EtOH to DMSO, the MGs in EtOH were centrifuged and then redispersed in DMSO. This process was repeated and finally diluted to $6.0 \mathrm{wt} \%$ in DMSO.

\section{Perovskite/MG composite film formation}

ITO-coated glass substrates $(20 \Omega / \mathrm{sq})$ were cleaned by ultrasonication in a $1.0 \mathrm{wt} \%$ Hellmanex solution, rinsed with water, followed by IPA, $\mathrm{NaOH}(2.5 \mathrm{M})$ and then rinsed with water and dried. A $\mathrm{TiO}_{2}$ hole blocking layer $\left(\mathrm{bl}-\mathrm{TiO}_{2}, 45 \mathrm{~nm}\right.$ ) was spin-coated at $2000 \mathrm{rpm}$ for $60 \mathrm{~s}$ onto the ITO using TDP solution in 1-butanol $(0.30 \mathrm{M})$ and subsequent heating at $125^{\circ} \mathrm{C}$ for $5 \mathrm{~min}$. After that, the bl- $\mathrm{TiO}_{2}$ film was annealed at $500{ }^{\circ} \mathrm{C}$ for $30 \mathrm{~min}$. Upon cooling to room temperature a $\mathrm{MAPbI}_{3}$ precursor solution containing MGs (total volume $100 \mu \mathrm{L}$ ) was spin-coated onto $\mathrm{ITO} / \mathrm{bl}-\mathrm{TiO}_{2}$ substrate at $4000 \mathrm{rpm}$ for $25 \mathrm{~s}$. During the spin coating process, toluene (200 $\mu \mathrm{L})$ was dripped onto the surface at a uniform rate onto the film during the last $10 \mathrm{sec}$. The precursor solution was adapted from the literature ${ }^{56}$ and contained $\mathrm{MAI}, \mathrm{PbI}_{2}, \mathrm{MACl}$ and DMSO (1:1:0.6:1 molar ratio) in $1.0 \mathrm{~mL}$ of DMF, as well as MGs in DMSO at various concentrations. The nominal compositions of the $(x$, 
y) films studied are shown in Figure 1B. An example preparation is given for the (30, 3.0) film. The precursor perovskite solution contained MAI (0.377g), $\mathrm{PbI}_{2}(1.093 \mathrm{~g}) \mathrm{MACl}(0.107 \mathrm{~g})$ and DMSO $(0.0990 \mathrm{~g})$ in DMF $(1.0 \mathrm{~mL})$ and the total concentration was $60 \mathrm{wt} . \%$ The precursor / MG mixed solution was prepared by mixing the perovskite precursor solution $(0.50 \mathrm{~mL}, 60 \mathrm{wt} \%)$ with MGs in DMSO (0.50 mL, $6.0 \mathrm{wt} . \%)$. The mixed solution was sonicated in ultrasonic bath for 10 min before deposition. The films were annealed at $100{ }^{\circ} \mathrm{C}$ for $10 \mathrm{~min}$ and consisted of glass/ITO/bl- $\mathrm{TiO}_{2} /(x, y)$. The $\mathrm{Cl}$ content of the perovskite part of the $(x, y)$ films is assumed to be negligible. All films were stored in a desiccator over $\mathrm{P}_{2} \mathrm{O}_{5}$ in the dark until further investigation.

\section{Physical Measurements}

Dynamic light scattering (DLS) measurements were conducted using a Malvern Zetasizer Nano ZS instrument and provided the z-average diameter $\left(d_{z}\right)$. The top view SEM images were obtained using a Philips XL30 FEGSEM. The cross-section SEM images were obtained using a Carl Zeiss Sigma FE-SEM. The samples were coated with Au or Pd. AFM images were obtained using either a Bruker Multimode 8 or a Bruker Catalyst; images were captured in ScanAsyst ${ }^{\mathrm{TM}}$ (Peak Force Tapping) mode. UV-visible spectra were recorded using a Perkin Elmer Lamda 25 UV-Visible spectrometer. The AVT was measured between $370-740 \mathrm{~nm}$ because we aim at future aesthetic applications for our thin films ${ }^{35,57}$. XRD patterns were obtained using a Bruker D8 Advance diffractometer $(\mathrm{Cu}-\mathrm{K} \alpha)$. The films were prepared under nitrogen atmosphere and measured in an airtight holder. Photoluminescence (PL) spectra were obtained using an Edinburgh Instruments FLS980 spectrometer. The beam was incident on the film surface side and an excitation wavelength of $480 \mathrm{~nm}$ was used.

\section{X-ray photoelectron spectroscopy}

X-ray photoelectron spectroscopy (XPS) measurements were performed with a SPECS XPS spectrometer, equipped with a monochromated $\mathrm{Al} \mathrm{K}_{\alpha} \mathrm{X}$-ray source that can produce X-rays with photon energy of $1486.7 \mathrm{eV}$. Photoelectrons produced were collected by a $150 \mathrm{~mm}$ hemispherical energy analyzer (Phoibos 150 SPECS). Binding energies (BEs) were calibrated to C 1s from 
$\mathrm{CH}_{3} \mathrm{NH}_{3} \mathrm{PbI}_{3}$ (MAPI) at $285.3 \mathrm{eV},{ }^{58}$ or to $\mathrm{C} 1 \mathrm{~s}$ from adventitious carbon at $284.8 \mathrm{eV}{ }^{59}$ All XPS spectra were analysed using CasaXPS software ${ }^{60}$. A Shirley background and pseudo-Voigt (GL(30)) function (30\% Lorentzian and $70 \%$ Gaussian) were applied to fit the spectra acquired ${ }^{61}$. $\mathrm{BE}$ values are quoted to an accuracy of $\pm 0.1 \mathrm{eV}$ due to instrumental precision. To obtain the surface composition of the films, the built-in CasaXPS Kratos sensitivity factors were used to calculate the stoichiometries.

\section{Device fabrication and characterization}

The procedure to prepare the glass/ITO/bl- $\mathrm{TiO}_{2} /(x, y)$ films was described above. Film fabrication, including Spiro deposition, was conducted inside a nitrogen-filled glovebox (humidity 2\%). CBZ was used as the HTM solvent at room temperature. LiTFSI $(4.8 \mu \mathrm{L}, 520 \mathrm{mg} / \mathrm{ml})$ and TBP $(8.0 \mu \mathrm{L})$ were also added to the Spiro solution. The Spiro hole transfer matrix films (200 nm) were formed by spin coating at $4000 \mathrm{rpm}$ for $20 \mathrm{~s}$ onto the perovskite films. The planar devices were coated with a gold layer $(70 \mathrm{~nm})$ using thermal evaporation. For the devices containing a meso-TiO ${ }_{2}$ layer, 18NRT was diluted 1:10 with $\mathrm{EtOH}$ and then $75 \mu \mathrm{L}$ was spin coated at $5000 \mathrm{rpm}$ for $30 \mathrm{sec}$ on the bl- $\mathrm{TiO}_{2}$ layer. The layer was then annealed at $500{ }^{\circ} \mathrm{C}$ for $30 \mathrm{~min}$. The current density-voltage $(J-V)$ characteristics were measured using a Keithley 2420 Sourcemeter and $100 \mathrm{~mW} \mathrm{~cm} \mathrm{~cm}^{-2}$ illumination (AM 1.5G) and a calibrated NREL certified Oriel Si-reference cell. An Oriel solar simulator (SOL3A) was used for these measurements. The active area of the devices $\left(0.080 \mathrm{~cm}^{2}\right)$ was determined using a square aperture within a mask. The data shown are from the reverse scan $\left(V_{\mathrm{oc}}\right.$ to $\left.J_{\mathrm{sc}}\right)$ and the sweep rate was $100 \mathrm{mV} \mathrm{s}^{-1}$.

\section{RESULTS AND DISCUSSION}

Thick perovskite films prepared using sub-micrometer microgels; why size matters

A critical question concerning how swellable polymer colloids can distribute within perovskite films is what effect the use of sub-micrometer MGs has on the morphology. To address this question we first consider thick MG/perovskite films. Here, new sub-micrometer PNVF-NVEE 
MGs are introduced. DLS data (Fig. S1A) showed that the MG $d_{z}$ values increased from $354 \mathrm{~nm}$ to $495 \mathrm{~nm}$ when the MGs were transferred from EtOH to DMSO. This increase is because DMSO, which is a thermodynamically good solvent for PNVF-NVEE, swelled the MGs. These diameters are more than a factor of two smaller than the MGs used in our previous study ${ }^{30}$. The MG particle volume swelling ratios $\left(Q_{M G}\right)$ estimated from the DLS data (Fig. S1A) is 2.7. The MGs had low polydispersity as shown by SEM images (see Fig. 2A). The MGs deposited from EtOH had a number-average diameter from SEM (Fig. S1B) of $336 \mathrm{~nm}$ (Table S1). The MGs deposited from DMSO (Fig. S1C) had a larger diameter of $731 \mathrm{~nm}$ as measured using SEM. This difference is because MGs are highly deformable and flatten when deposited from the swollen state ${ }^{30,62}$.

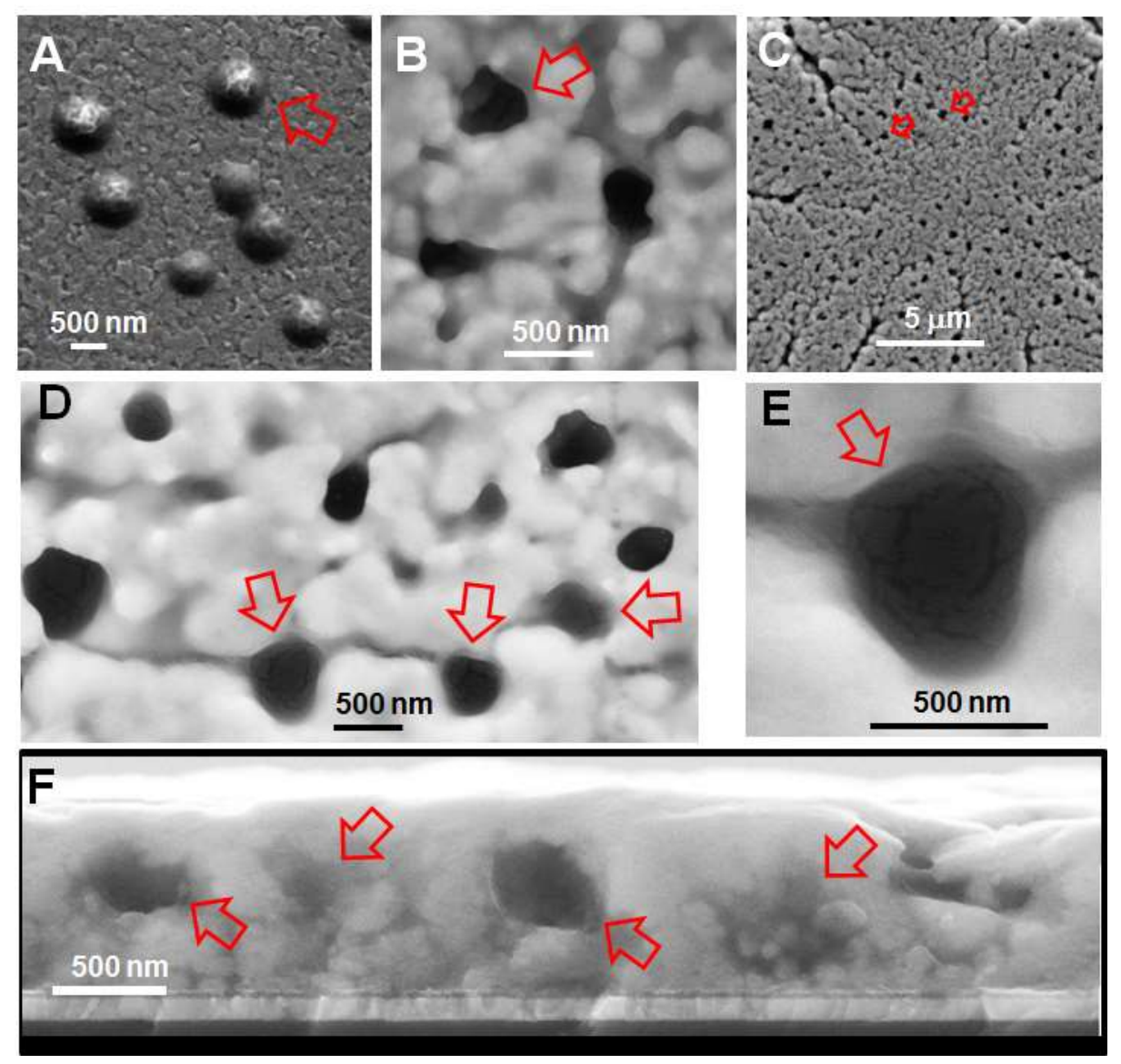

Figure 2. SEM images for (A) MGs deposited from DMSO. SEM images are shown in (B) and (C) for thick (30, 4.0) films. (D) and (E) show SEM images for (30, 3.0) films. (F) Cross-section SEM image for a $(30,4.0)$ film. The red arrows highlight MGs which are dark and partially transparent.

The vertical blue line in Fig. 1B shows the mixture compositions used to prepare the thick films. 
The perovskite precursor concentration (x) was fixed $30 \%$ and the MG concentration (y) varied. Figures 2B and 2C show top view SEM images for a film prepared using 4.0\% MG, i.e., (30, 4.0). Black regions are evident (arrows), which are MGs. This can be seen more clearly from the SEM images for the $(30,3.0)$ film shown in Fig. 2D and 2E. The latter figure has an appearance resembling a pool of melted ice. The density of PNVF-NVEE $\left(\sim 1.0 \mathrm{~g} / \mathrm{cm}^{3}\right)$ is a factor of four lower than that for MAPI ${ }^{63}\left(4.1 \mathrm{~g} / \mathrm{cm}^{3}\right)$ which made the MGs relatively difficult to visualise by SEM. The dark MGs created pores and perovskite could sometimes be seen through the MG. SEM images for all $(30, y)$ films with $y=0,1.0,3.0$ and $4.0 \%$ are shown in Fig. S2. The average MG sizes for the (30, y) films prepared using $y=1.0,3.0$ and 4.0 were $542 \pm 75 \mathrm{~nm}, 454 \pm 65$ and $342 \pm 73 \mathrm{~nm}$, respectively. Comparison of these diameters with those discussed above from SEM for the MGs deposited from DMSO $(731 \mathrm{~nm})$ and EtOH $(336 \mathrm{~nm})$ shows that the MGs were increasingly constrained laterally within the $(30, y)$ composite films as $y$ increased.

We measured SEM cross-sectional images for the $(30,4.0)$ film (see Fig. 2F). The SEM images show dark spherical structures in the interior of the film (arrows) that are MGs. This is direct evidence for buried, encapsulated, MGs within the perovskite films and is a new observation. The presence of buried (and surface) MGs differs from the morphology studied earlier where only surface pores were evident ${ }^{30}$. This difference is because in the present case the MG diameter was less than the film thickness. Being able to bury MG particles within perovskite films has interesting potential for future composites. It follows that if the MG particle diameter is smaller than the perovskite film thickness the particles can be fully encapsulated within the perovskite film. Hence, MG size plays an important role in determining perovskite/MG composite film morphology.

Before proceeding to ST films, the transmittance spectra for the thick $(30, y) y=0,1,3$ and 4 films were measured. These thick film data are used as a reference for the ST films which are studied below and it will be shown that thickness makes a large difference to the optoelectronic properties. All these thick films were strongly absorbing with low transmittance over most of the visible range (see Fig. 3A). Increasing MG concentration (y) caused the average visible transmittance (AVT) to 
decrease (Fig. 3B), which is due to increased light scattering from the two phase composite films with increasing $y$. (We demonstrate the opposite trend for ST films below.) To probe the effects of $y$ on charge transfer PL spectra were measured (Fig. 3C). The PL intensity increased with increasing $y$, which indicates that non-radiative recombination became increasingly less efficient. Furthermore, a significant blue shift of the wavelength at maximum PL intensity $\left(\lambda_{\max }\right)$ occurred with increasing $y$ (see Fig. 3D). This blue shift is a new observation for perovskite/MG films. The blue shift is far more pronounced for ST perovskite/MG films and is discussed below.
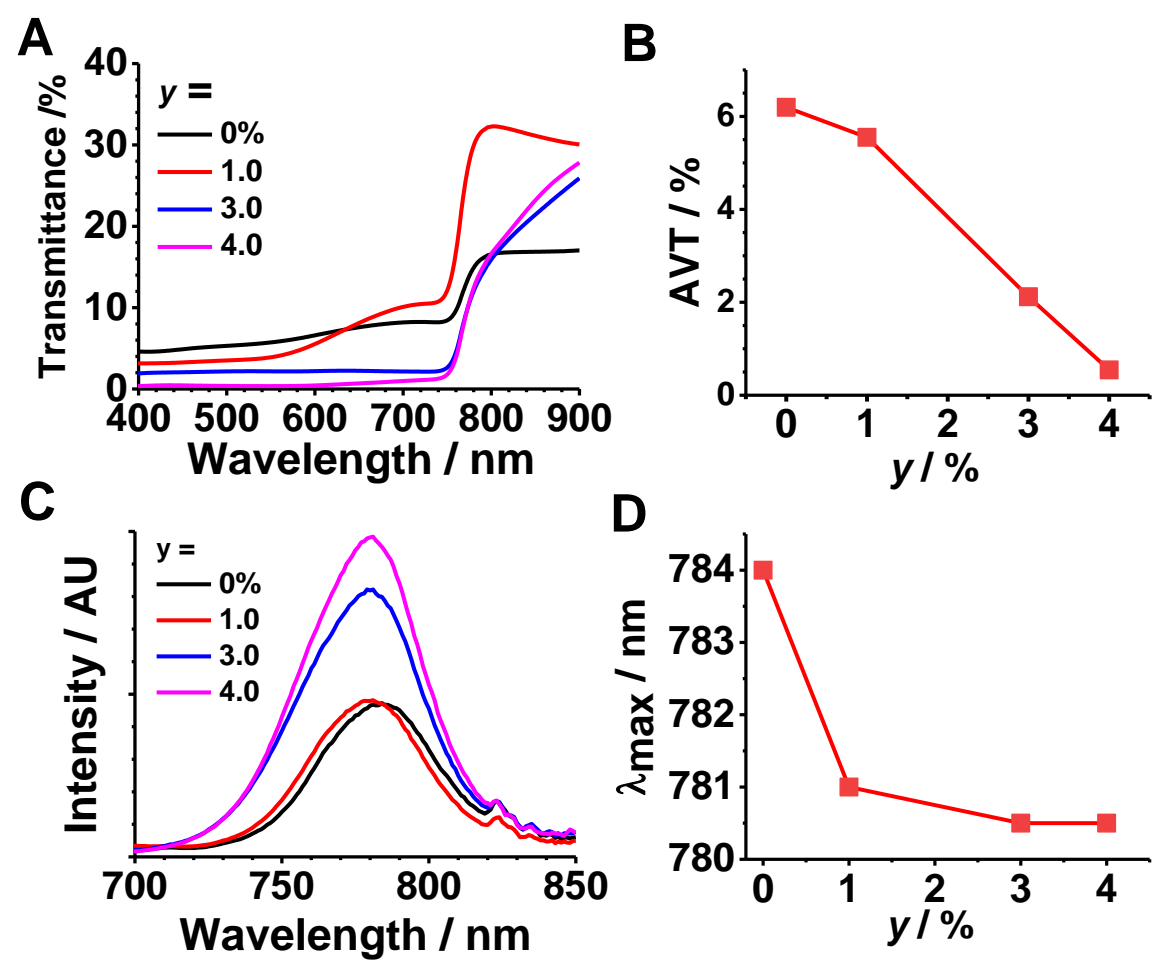

Figure 3. (A) Transmittance spectra for the thick $(30, y)$ films. (B) The effect of MG concentration (y) on the average visible transmittance (AVT) of $(30, y)$ films. (C). PL spectra for $(30, y)$ films. (D) The effect of $y$ on the wavelength at maximum PL intensity $\left(\lambda_{\max }\right)$ for the $(30, y)$ films.

\section{Thin semi-transparent films and solar cells prepared using sub-micrometer microgels}

To prepare ST PSCs with good performance it is important that high film coverage is maintained as the thickness decreases. Preventing pinhole formation is challenging for thin films ${ }^{64}$. The thick (30, 3.0) and (30,4.0) films discussed above had the highest MG contents and films with high coverage of the substrates (see Fig. S2A and S2B). These composite films have nominal MG weight fractions 
of $W_{M G}=100 y /(x+y)$ of $\sim 9.0$ and $12.0 \%$, respectively. We therefore selected the average $W_{M G}$ value of $\sim 10.5 \%$ to prepare thin $(x, y)$ films. This was achieved by systematically decreasing $x$ and $y$ whilst keeping $W_{M G}$ constant. The compositions used for preparing these thin films are shown in Fig. 1B (red diagonal line).

SEM images for the $(x, y)$ films (Fig. 4A - E) show dramatic changes as the films became thinner, i.e., as $x$ and $y$ decreased. Measured film thicknesses are shown in Fig. 4F. The latter followed a power law relationship with increasing total precursor concentration $(x+y)$. The SEM images show that as the films became thinner the MGs resided on the surface of the thin films. (MGs are highlighted with red arrows.) The MG particles could no longer be buried when the film thickness was $120 \mathrm{~nm}$ (i.e., for the $(25,3)$ film) or less. The thinnest composite film $((5.0,0.6))$ was too thin for thickness measurements to be obtained. However, black MGs were evident (Fig. 4E). Fig. 4G depicts our proposal for the arrangement of the MGs in the perovskite/MG films. For the thin films, the MGs were surrounded by a relatively thin layer of perovskite that crystallized as the MG collapsed. The morphologies of the thinnest perovskite/MG films (Fig. 4D and E) are profoundly different to those of control MG-free films (Fig. 4H and I). The control MG-free films were irregular and had many large pinholes (highlighted with yellow arrows). This discontinuous morphology for the control MG-free films is the result of partial dewetting of the $\mathrm{TiO}_{2}$-coated ITO and tends to become pronounced for thin perovskite films as originally reported by Eperon et al. ${ }^{35}$ and more recently by Marongiu et $\mathrm{al}^{65}$. Indeed, micro-islands can form under such circumstances and have been used to construct ST PSCs ${ }^{35,49,65,66}$. In contrast the MG-containing films contained collapsed MGs as depicted in Fig. 4G, which prevented pinhole formation. Hence, inclusion of MGs decreased the proportion of pinholes for thin perovskite films. Even though the MGs appear as holes due to their relatively low contrast, they are in fact insulating polymer particles that have flattened. This morphology is preferred from the solar cell perspective compared to that of the thin control MG-free films (Fig. 4H and 4I) because such MG particles should prevent contact of Spiro with the underlying $\mathrm{TiO}_{2}$-coated ITO in devices. 

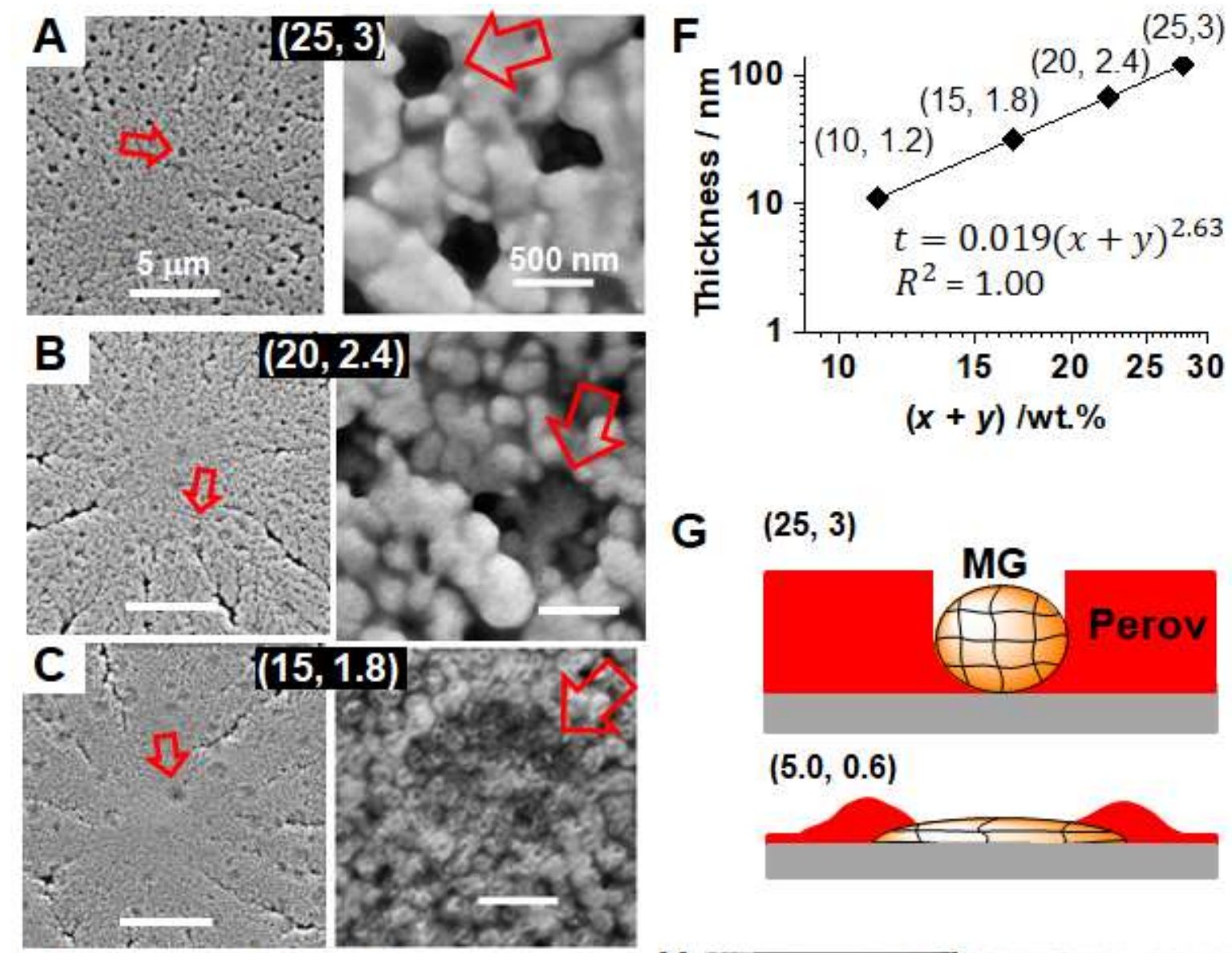

\section{$(5.0,0.6)$}
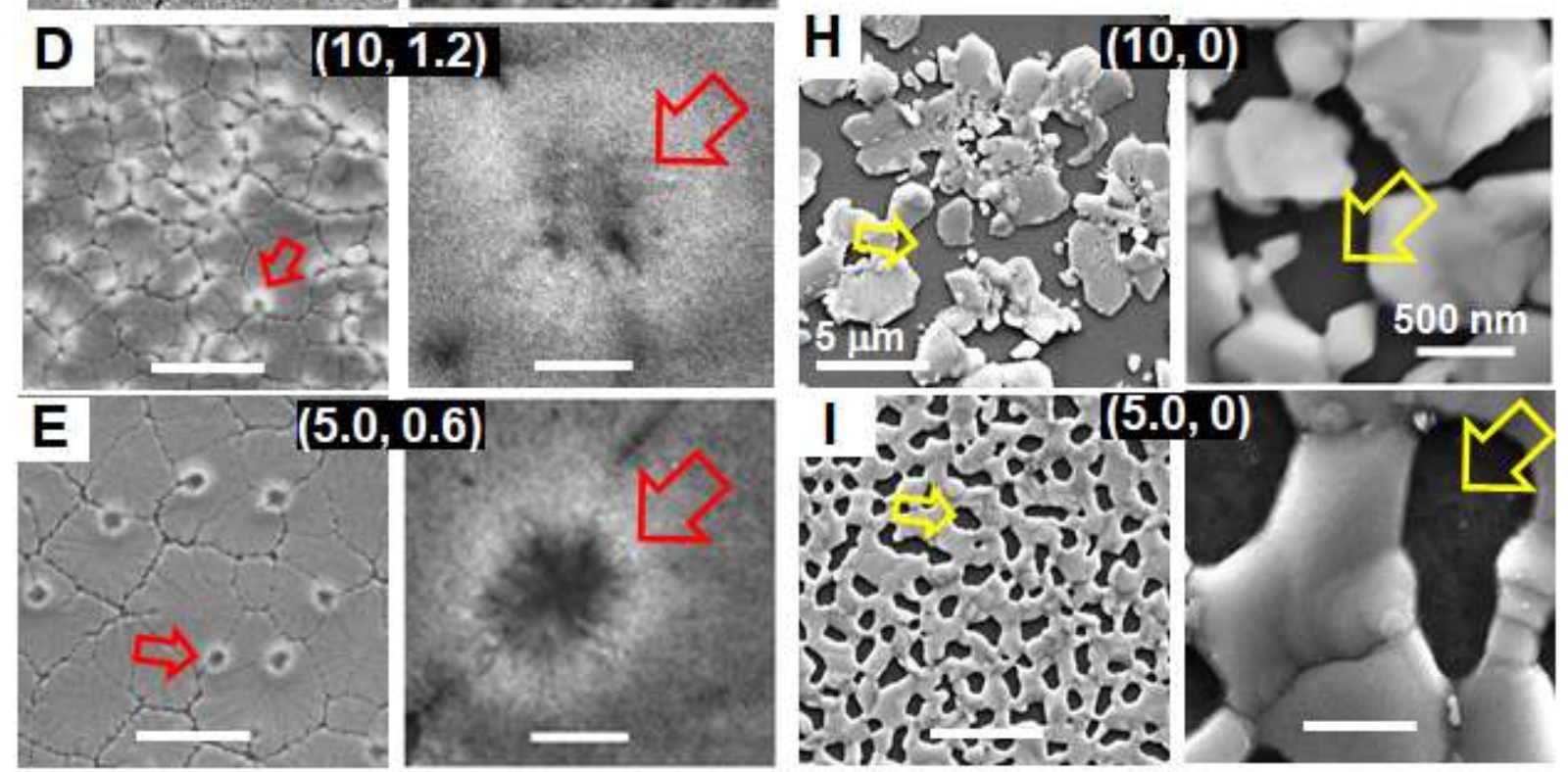

Figure 4. (A) - (E) SEM images showing the morphology of the thin $(x, y)$ films with decreasing perovskite precursor $(x)$ and MG $(y)$ concentrations. The red and yellow arrows highlight MGs and pinholes, respectively. The MGs appear dark or almost transparent. (F) Thickness of various perovskite/MG films. (G) Depiction of proposed morphological changes as the films became thinner. (H) and (I) show SEM images of MG-free controls. The scale bar values shown in the first row apply to all images. 
X-ray scattering patterns were measured for $(20,2.4),(10,1.2)$ and the MG-free $(20,0)$ and $(10,0)$ films (see Fig. S3). $\mathrm{PbI}_{2}$ was absent from all films which shows excellent conversion. Furthermore, there is a noticeable increase in the (110) peak broadness for the MG-containing $(10,1.2)$ and $(20$, 2.4) films compared to the respective MG-free $(10,0)$ and $(20,0)$ films. This indicates that the grain size decreased in the presence of the MGs. The $(10,1.2)$ and $(20,2.4)$ films showed multiple perovskite peaks and evidence of a more polycrystalline structure. In contrast $(10,0)$ and $(20,0)$ films showed fewer peaks and evidence of more preferred growth of larger grains, which agrees with the SEM images (compare Fig. 4D to 4H). The presence of polycrystalline films with relatively small grains implies that there were more nucleation sites for crystal growth in the presence of the MGs. Such a result could be expected if the MGs slowly released concentrated perovskite precursor as they de-swelled, which created new nucleation sites.

Examination of the SEM image for the (5.0, 0.6) film (Fig. 4E) reveals what appear to be circular ridges around the MGs. AFM data were obtained for the same system and "volcano-like" objects were apparent (see Fig. S4). The average peak-to-peak distance was $876 \pm 56 \mathrm{~nm}$. This distance is sufficiently large to accommodate a flattened MG particle as evidenced by comparison with Fig. 2A. The MG particles had volume fraction of 0.33 in the composite films based on the film composition and the densities of each component (above). However, the effective volume fraction of the MGs is likely to have been > 0.33 when DMSO was present because the MGs swelled in DMSO with $Q_{M G}=2.7$ (above). Hence, a large proportion of the precursor solution is likely to have been present within swollen MG particles prior to final solvent evaporation. This was gradually released as the MGs de-swelled during drying. However, this process would have been relatively slow because of the constraints of solvent permeating through a crosslinked network ${ }^{67}$. The cartoon shown in Fig. 4G (lower) depicts the final thin film and is consistent with the AFM data (Fig. S4).

To confirm our hypothesis that the MGs delayed perovskite crystallization digital photographs were taken of the MG-containing $(20,2.4)$ and the MG-free $(20,0)$ films on glass during annealing at 100 ${ }^{\circ} \mathrm{C}$ (See Fig. 5). The dark perovskite began to form at the edges of the $(20,2.4)$ film after 10 sec and 
this was complete after $17 \mathrm{sec}$. In contrast, the $(20,0)$ film showed formation of the perovskite phase after only $5 \mathrm{sec}$ and film formation was complete after $10 \mathrm{sec}$. (A video of these processes is shown in Movie S1.) The inclusion of the MGs increased the time required for perovskite film formation by up to a factor of two. Hence, the MGs modulated perovskite crystallization.

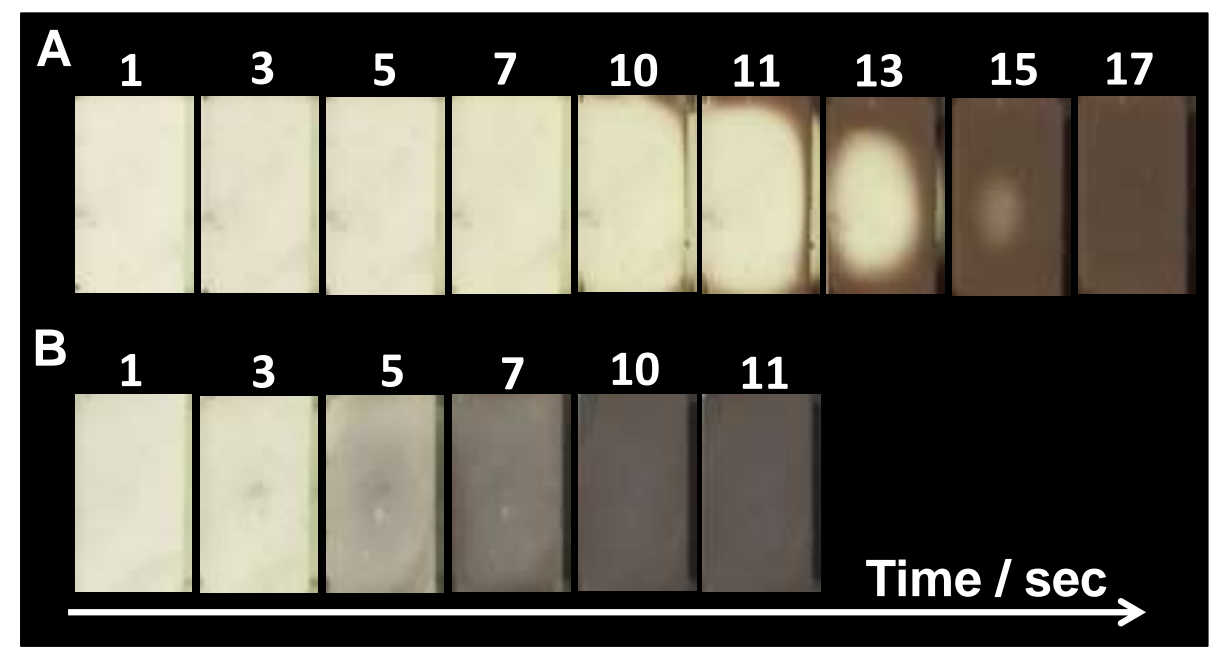

Figure 5. Digital photographs of the formation of (A) $(20,2.4)$ and $(\mathbf{B})(20,0)$ films on glass when heated at $100{ }^{\circ} \mathrm{C}$ by a hotplate for the times (shown). The film dimensions were $15 \mathrm{~mm}$ x $20 \mathrm{~mm}$.

To probe possible MG-perovskite interactions we used XPS to examine the thin $(10,1.2)$ film. A thick MG-free perovskite film $(39,0)$ was used as a control. The latter film was selected because it had the best coverage (see Fig. S5) among the MG-free samples. We also used a perovskite-free MG film as a control. The $\mathrm{N}$ 1s XPS spectrum of the perovskite-free MG film (Fig. 6A) shows a single component centred at $399.5 \mathrm{eV}$ binding energy $(\mathrm{BE})$, which is assigned to the $\mathrm{O}=\mathrm{C}-\underline{\mathrm{NH}}$ groups $^{68-70}$ from the MG. The N 1s XPS spectra for the MG-free $(39,0)$ and $(10,1.2)$ films (Fig. 6A) have two components. A high BE peak is present in both films at $402.5 \mathrm{eV}(39,0)$ and 402.2 $\mathrm{eV}(10,1.2)$ which is ascribed to the $\mathrm{CH}_{3} \mathrm{NH}_{3}{ }^{+}$component of MAPI. ${ }^{58}$ The $0.3 \mathrm{eV} \mathrm{BE}$ shift towards low BE side suggests that the MG contributes electron density to MAPI. Neutral $\mathrm{CH}_{3} \mathrm{NH}_{2}$ molecules contribute to a weak shoulder for the $(39,0)$ film at $400.8 \mathrm{eV}^{71}$. For the $(10,1.2)$ film a dominant low-BE peak is present at $400.4 \mathrm{eV}$ due to the $\mathrm{MG}$ which has shifted by $0.9 \mathrm{eV}$ compared to the parent MG signal. This peak is due to MGs at the film surface and the BE shift suggests that 
the $\mathrm{O}=\mathrm{C}-\underline{\mathrm{N} H}$ - groups donate electron density to MAPI.
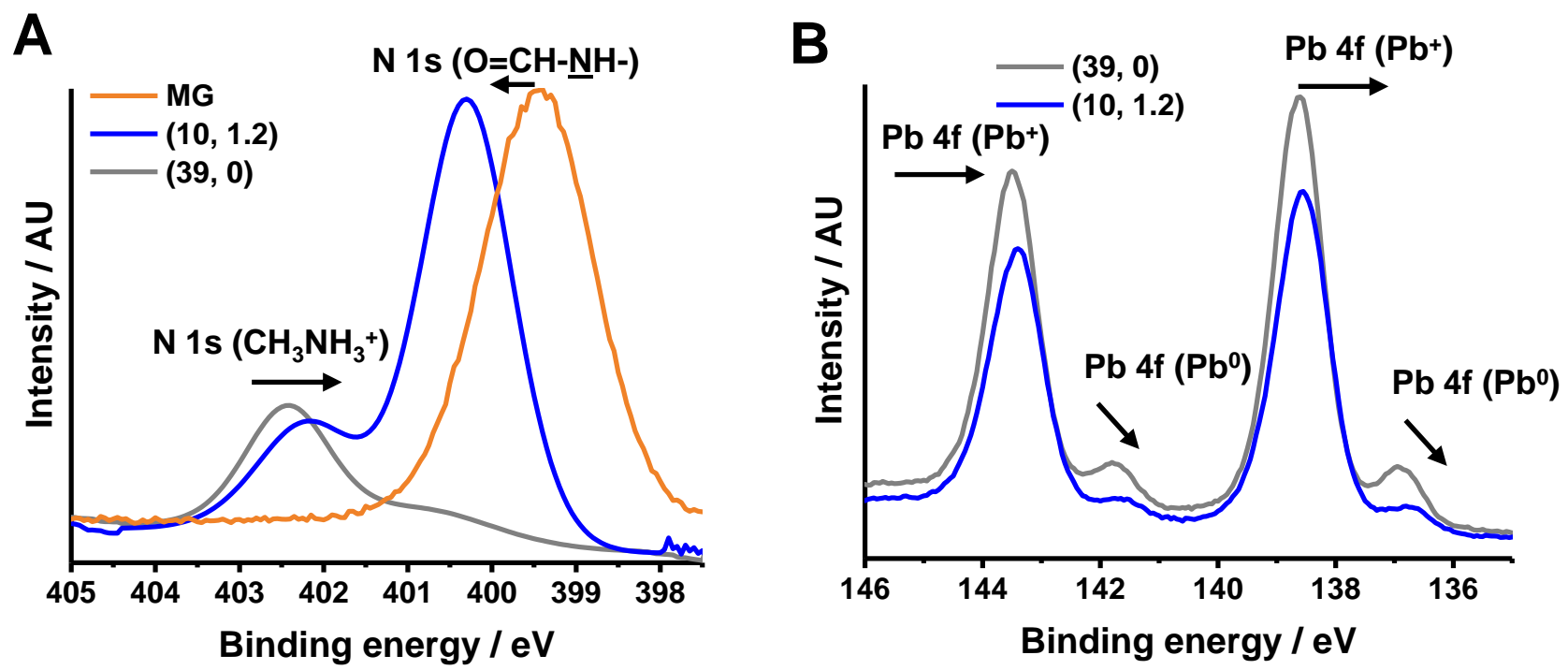

Figure 6. XPS core-level (A) N 1s and (B) Pb 4f spectra measured for various films (shown). The arrows in (A) show the binding energy shifts. The arrows in (B) show that BE shifted to lower values when MG was present.

$\mathrm{Pb} 4 \mathrm{f}$ spectra (Fig. 6B) also show evidence that the MGs interact with the perovskite. The spectra for the $(39,0)$ film shows a spin-orbit split doublet from $\mathrm{Pb}^{2+} 4 \mathrm{f}_{7 / 2}$ at $138.6 \mathrm{eV}^{58}$. It is apparent that in addition to the main peak there is also under-coordinated $\mathrm{Pb}^{0}$ at $136.9 \mathrm{eV} \mathrm{BE}^{58}$. Undercoordinated $\mathrm{Pb}$ has been reported for perovskite films ${ }^{25}$. Intriguingly, the signal decreases from $12 \%$ (for the $(39,0)$ film) to $6 \%$ (for the $(10,1.2)$ film) with respect to $\mathrm{Pb}$. This suggests that the MG coordinates to some of this $\mathrm{Pb}$ species and donates electron density. Such behaviour has been reported for donor- $\pi$-acceptor molecules ${ }^{25}$ but not for non-conjugated polymer additives to the best of our knowledge. Hence, our XPS results show that the MG particles strongly interact with the perovskite and this probably occurs through complex formation with $\mathrm{Pb}$.

The XPS data also enabled the composition of the films to be probed. The N/Pb stoichiometries for the $(10,1.2)$ and $(39,0)$ films were $2.0 \pm 0.2$ and $0.8 \pm 0.2$, respectively. Using the molecular weight of the perovskite (MAPI) and that for the poly(NVF-NVEE) copolymer which comprised the MGs, this ratio corresponds to $W_{M G} \sim 10.3 \%$. The latter agrees closely to the $(10,1.2)$ film $W_{M G}$ 
value of $\sim 10.5 \%$ used during film preparation. Hence, these data confirm the presence of the MGs in the composite perovskite/MG films. The N/Pb value for the $(39,0)$ film is as expected for MAPI.

Transmittance spectra for the thin films were measured for the thin films (see Fig. 7A). These data show that the transmittance increased dramatically as the composition moved toward the thinnest ST systems, i.e., as $x$ and $y$ decreased. Figure 7B shows that the AVT values plotted as a function of $x$. Clearly, the AVT increased as $x$ decreased. The $(10,1.2)$ film had an AVT of $46.8 \%$ and is above the AVT threshold of $25 \%$ for solar window applications ${ }^{38}$. This suggestion is demonstrated by the photograph of the building viewed through the film. Remarkably, Fig. 7B shows that a cross-over of AVT occurred when $x$ decreased to below 20\%. The AVT values of the perovskite/MG composite thin films are higher than those for the respective perovskite-only films. (Transmittance spectra for the perovskite-only films appear in Fig. S6.) This trend is in contrast to that observed for thick (30, y) films (see Fig. 3B) where the AVT for the MG-free film $(y=0)$ was much higher than those containing MGs ( $y=1.0,3.0$ and 4.0). We attribute this change in AVT to the films becoming so thin that the MGs were not able to be engulfed by perovskite. Additionally, the MGs promoted formation of thin ST films that were relatively pinhole-free. Consequently, the perovskite/MG ST films had lower refractive index variation and hence less light scattering. 

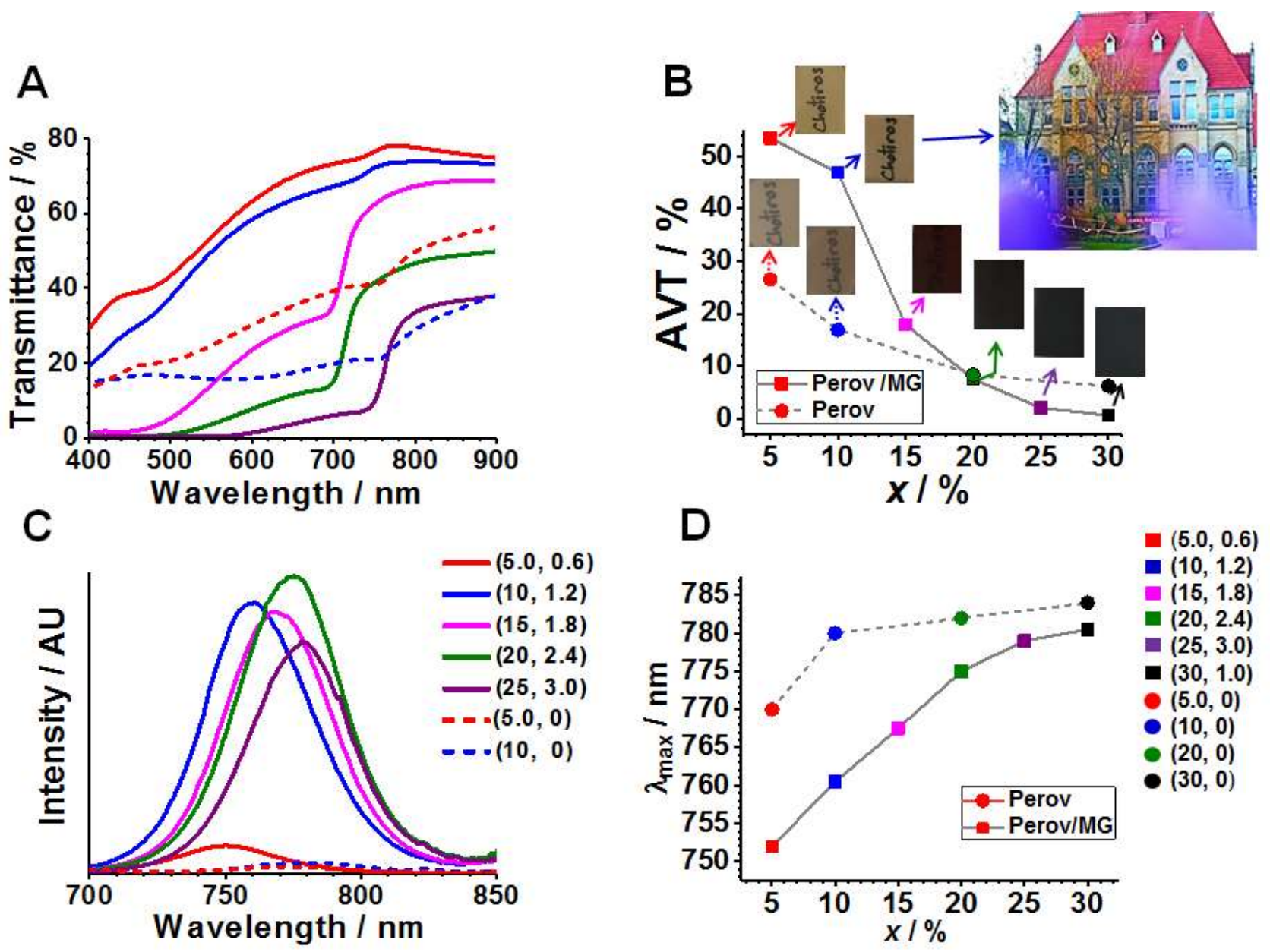

Figure 7. (A) Transmittance spectra for the thin $(x, y)$ films. (B) AVTs for the films determined from the spectra in (A). Digital photographs for the films $(15 \mathrm{~mm}$ x $20 \mathrm{~mm})$ are shown as well as a photo of a building through the (10, 1.2) film. (C) PL spectra for the thin films. (D) Variation of the wavelength at maximum PL intensity with $x$ for the films. The legend in (C) also applies to (A). The legend in (D) also applies to (B).

The PL spectra of the thin films show two interesting trends (Fig. 7C). (PL spectra for the full range of MG-free films are shown in Fig. S7A.) Firstly, the PL intensities of the MG-containing thin films are about an order of magnitude higher than those for the respective MG-free films (see Fig. S7B). Secondly, the PL spectra show a large blue shift of the wavelength of maximum PL intensity $\left(\lambda_{\max }\right)$ as $x$ decreased (See Fig. 7D). These trends are similar to those observed for the thick films (Fig. 3C and 3D). However, both trends are much more pronounced for the thin films. There are two possible causes for these effects. The first is due to a decrease in the grain size as noted above. Such blue shifts are known for perovskites as the grain size decreases ${ }^{72,73}$ and is apparent for the MG-free 
films, but to a lesser extent (Fig. 7D). Additionally, we suggest that MG-interaction with the perovskite noted above resulted in passivation. The latter is well known to cause a blue-shift in the PL spectra ${ }^{74}$ and may increase PL intensity because of less non-radiative energy transfer.

Several authors have reported that a decrease in perovskite grain size causes a blue shift. Zhang et al. ${ }^{73}$ reported a $0.082 \mathrm{eV}$ blue shift with decreasing pore diameter of constrained MAPI. De Bastiani et al. $^{72}$ reported that mesostructured MAPI had a blue shifted absorption compared to a flat film. Ghosh et al. ${ }^{75}$ and Tian et al. ${ }^{76}$ also reported a blue shift of the PL as the crystal size deceased. The well accepted causes for such blue shifts for perovskites are doping with bromide or quantum size effects $^{73}$. Neither of these effects are likely in the present study. The surface area per unit mass of the grains is approximately inversely proportional to the grain size. Hence, decreasing the grain size increases the proportion of perovskite at the grain boundary. Because such perovskite is available for surface passivation the increased blue shift observed as $x$ decreases in Fig. 7D is likely due to more extensive passivation.

Solar cells were constructed using the ST films and the planar geometry without a meso- $\mathrm{TiO}_{2}$ layer as shown in Fig. 8A. In addition, devices were also prepared using a thin meso- $\mathrm{TiO}_{2}$ layer and will be discussed below. The thickness of the top Au electrode was $70 \mathrm{~nm}$. (Device performance parameters are shown in Table S2.) These devices test the concept of establishing efficient PSCs using these new ST films. Such data are an essential precursor for construction of ST PSCs. We selected the $(10,1.2)$ film for this part of the study as it had the highest $x$ value for which the AVT was greater than $25 \%$. The average PCE for $(10,1.2)$ was $7.69 \%$. We also measured the PCE of devices prepared using the MG-free $(5.0,0)$ ST film. This control film had an AVT of $26.5 \%$. In that case the PCE was $4.93 \%$. The steady state current density for that system (Fig. 8C) continually increased with time, which contrasts to the $(10,1.2)$ film which was constant. The temperature of the $(5.0,0)$ film increased from $25{ }^{\circ} \mathrm{C}$ to $70{ }^{\circ} \mathrm{C}$ after $300 \mathrm{~s}$ during the measurement which was the likely cause of the increase in the current density. The PCE was relatively low for $(5.0,0)$ devices because of the high proportion of pinholes as can be seen from Fig. 4I. 
A

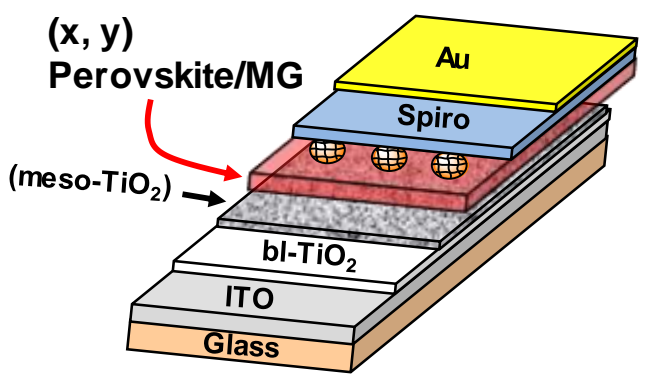

C

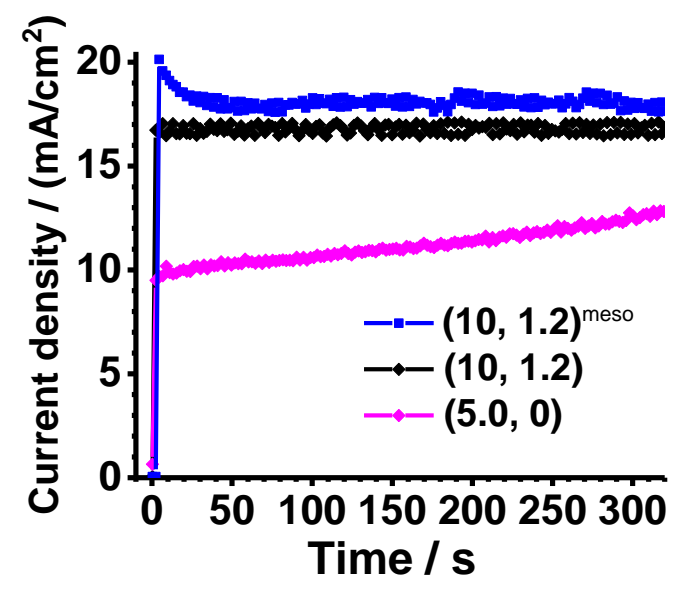

B

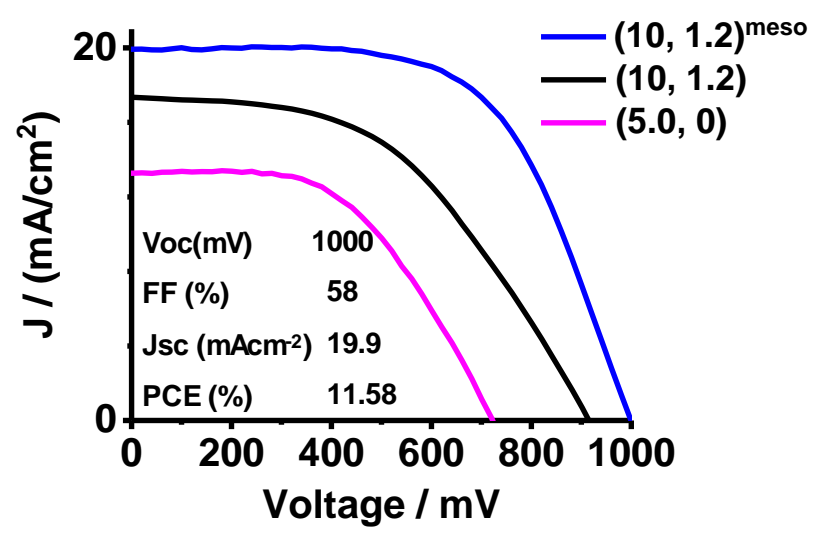

D

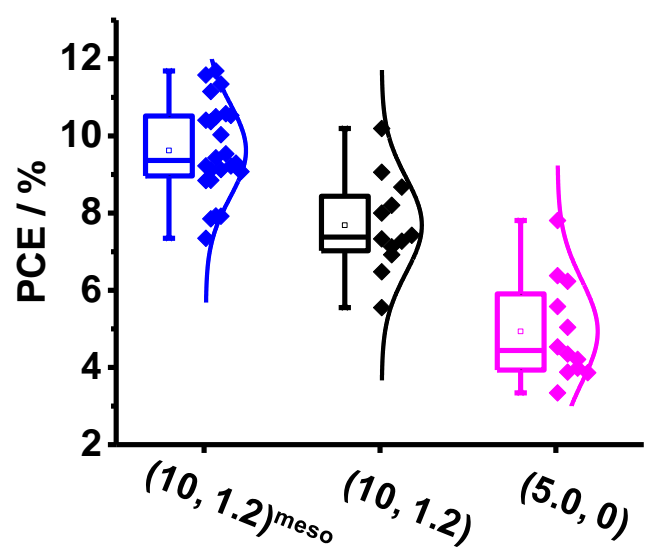

Figure 8. (A) The devices had either a planar architecture $((10,1.2)$ and $(5.0,0))$ or a thin layer of meso- $\mathrm{TiO}_{2}\left((10,1.2)^{\text {meso }}\right)$. (B) $J-V$ data for representative devices. (C) Time-dependent current density for $(10,1.2)$ and $(5.0,0)$ solar cells. (D) Box charts and PCE distributions for the solar cells. Device data for the best $(10,1.2)$ device are shown in $(B)$.

The PCE was further increased by adding a thin meso- $\mathrm{TiO}_{2}$ layer to the $(10,1.2)$ system, which is termed $(10,1.2)^{\text {meso }}$. The SEM of the $(10,1.2)^{\text {meso }}$ film and transmittance spectra for the film are shown in Fig. S8A and S8B, respectively. The morphology of the film is similar to that for $(10,1.2)$ from Fig. 4D. The AVT decreased to $40.7 \%$ as a consequence of the thin perovskite-filled meso$\mathrm{TiO}_{2}$ layer. However, the AVT remains much greater than $25 \%$. The best $(10,1.2)^{\text {meso }}$ device had a PCE of $11.5 \%$ (Fig. 8B) and the average PCE is $9.62 \%$, which is $25 \%$ higher than for measured for $(10,1.2)$. The PCE values for the devices measured are compared in Fig. 8D. The average PCE and AVT values for $(10,1.2)^{\text {meso }}$ and $(10,1.2)$ devices compare favourably to those reported in the 
literature as shown by Figure S9. Specifically, the PCE for $(10,1.2)$ is relatively high given the large AVT value. Hence, the data establish proof-of-concept for using MGs to improve the performance of ST PSCs. The effect of added MGs on the stability of the devices is beyond the scope of the present study and will be investigated in future work.

\section{Conclusions}

In this study we investigated perovskite films containing new, sub-micrometer poly(NVF)-based MGs. The MGs were shown to become enclosed in thick perovskite films when the film thickness was larger than the $\mathrm{MG}$ diameter.We found remarkable differences for the thick and thin perovskite/MG composite films. When the MGs are enclosed within thick perovskite films the AVT is lower than the case when the MGs are absent. However, for thin ST films the MGs increased the AVTs and improve the film coverage by delaying crystallization. The MGs gave more uniform thin films with fewer pinholes compared to MG-free thin films and this is the primary reason why the PCE increased. The XPS and PL results indicate that the MGs passivated the perovskite films, which involved complex formation with $\mathrm{Pb}$. We also showed that $\mathrm{ST}$ films prepared using MGs with an AVT of $46.8 \%$ gave an average device PCE of $7.69 \%$. The latter value increased to $9.62 \%$ when a thin meso- $\mathrm{TiO}_{2}$ layer was used. These PCE values compare favourably to literature values and demonstrate very good potential for future ST PSC applications. Our approach of MGmoderated perovskite crystallization should be applicable to other perovskites, PSCs and potentially to tandem devices. In principle, the MGs could be prepared on the multi-tonne scale and the ST perovskite/MG film formation process is suitable for scale-up.

\section{ASSOCIATED CONTENT}

\section{Supporting Information}

Additional data and results that include: Movie showing delayed crystallization, dynamic light scattering and SEM data for microgels, lower magnification SEM for the thick films, X-ray 
scattering patterns, AFM and line profile for (5.0, 0.6) film, SEM for MG-free (30, 0) film, transmittance spectra for MG-free thin perovskite films, PL spectra and data for various thin films, SEM and transmittance data for $(10,1.2)^{\text {meso }}$, table of MG characterisation data and table of PSC performance data, a figure and table for comparison of the efficiency of the $(10,1.2)$ device with the literature. The Supporting Information is available free of charge on the ACS Publication website.

\section{ACKNOWLEDGMENTS}

The authors would like to thank The Royal Thai Government and National Science and Technology

Development Agency (NSTDA), Thailand for scholarship support. The authors thank the Wellcome Trust for equipment grant support to the EM Core Facility. 


\section{References}

1. Kojima, A.; Teshima, K.; Shirai, Y.; Miyasaka, T., Organometal Halide Perovskites as Visible-Light Sensitizers for Photovoltaic Cells. J. Amer. Chem. Soc. 2009, 131, 6050-6051.

\section{NREL Best Research-Cell Efficiency Chart Accessed 17/05/2019.}

3. Manser, J. S.; Christians, J. A.; Kamat, P. V., Intriguing Optoelectronic Properties of Metal Halide Perovskites. Chem. Rev. 2016, 116, 12956-13008.

4. Moia, D.; Gelmetti, I.; Calado, P.; Fisher, W.; Stringer, M.; Game, O.; Hu, Y.; Docampo, P.; Lidzey, D.; Palomares, E.; Nelson, J.; Barnes, P. R. F., Ionic-to-electronic current amplification in hybrid perovskite solar cells: ionically gated transistor-interface circuit model explains hysteresis and impedance of mixed conducting devices. Energy Environ. Sci. 2019, 12, 1296-1308.

5. deQuilettes, D. W.; Zhang, W.; Burlakov, V. M.; Graham, D. J.; Leijtens, T.; Osherov, A.; Bulović, V.; Snaith, H. J.; Ginger, D. S.; Stranks, S. D., Photo-induced halide redistribution in organic-inorganic perovskite films. Nature Commun. 2016, 7, 11683.

6. Carnie, M. J.; Charbonneau, C.; Davies, M. L.; Troughton, J.; Watson, T. M.;

Wojciechowski, K.; Snaith, H.; Worsley, D. A., A one-step low temperature processing route for organolead halide perovskite solar cells. Chem. Commun. 2013, 49, 7893-7895.

7. Stranks, S. D.; Eperon, G. E.; Grancini, G.; Menelaou, C.; Alcocer, M. J. P.; Leijtens, T.; Herz, L. M.; Petrozza, A.; Snaith, H. J., Electron-Hole Diffusion Lengths Exceeding 1 Micrometer in an Organometal Trihalide Perovskite Absorber. Science 2013, 342, 341-344.

8. Burschka, J.; Pellet, N.; Moon, S.-J.; Humphry-Baker, R.; Gao, P.; Nazeeruddin, M. K.; Grätzel, M., Sequential deposition as a route to high-performance perovskite-sensitized solar cells. Nature 2013, 499, 316.

9. Jeon, N. J.; Noh, J. H.; Kim, Y. C.; Yang, W. S.; Ryu, S.; Seok, S. I., Solvent engineering for high-performance inorganic-organic hybrid perovskite solar cells. Nature Mater. 2014, 13, 897. 10. Afzaal, M.; Yates, H. M.; Walter, A.; Nicolay, S.; Ballif, C., 1 cm2 CH3NH3PbI3 mesoporous solar cells with $17.8 \%$ steady-state efficiency by tailoring front FTO electrodes. $J$. 
Mater. Chem. C 2017, 5, 4946-4950.

11. Cai, F.; Cai, J.; Yang, L.; Li, W.; Gurney, R. S.; Yi, H.; Iraqi, A.; Liu, D.; Wang, T., Molecular engineering of conjugated polymers for efficient hole transport and defect passivation in perovskite solar cells. Nano Energy 2018, 45, 28-36.

12. Anizelli, H. S.; Stoichkov, V.; Fernandes, R. V.; Duarte, J. L.; Laureto, E.; Kettle, J.;

Visoly-Fisher, I.; Katz, E. A., Application of luminescence downshifting materials for enhanced stability of $\mathrm{CH} 3 \mathrm{NH} 3 \mathrm{PbI} 3(1-\mathrm{x}) \mathrm{Cl} 3 \mathrm{x}$ perovskite photovoltaic devices. Org. Electron. 2017, 49, 129134.

13. Zhang, H.; Nazeeruddin, M. K.; Choy, W. C. H., Perovskite Photovoltaics: The Significant Role of Ligands in Film Formation, Passivation, and Stability. Adv. Mater. 2019, 31, 1805702.

14. Wang, M.; Fu, Q.; Yan, L.; Guo, P.; Zhou, L.; Wang, G.; Zheng, Z.; Luo, W., Improving the Performance and Reproducibility of Inverted Planar Perovskite Solar Cells Using Tetraethyl Orthosilicate as the Antisolvent. ACS Appl. Mater. Interfaces 2019, 11, 3909-3916.

15. Zhang, H.; Chen, H.; Stoumpos, C. C.; Ren, J.; Hou, Q.; Li, X.; Li, J.; He, H.; Lin, H.; Wang, J.; Hao, F.; Kanatzidis, M. G., Thiazole-Induced Surface Passivation and Recrystallization of CH3NH3PbI3 Films for Perovskite Solar Cells with Ultrahigh Fill Factors. ACS Appl. Mater. Interfaces 2018, 10, 42436-42443.

16. Yang, W. S.; Park, B.-W.; Jung, E. H.; Jeon, N. J.; Kim, Y. C.; Lee, D. U.; Shin, S. S.; Seo, J.; Kim, E. K.; Noh, J. H.; Seok, S. I., Iodide management in formamidinium-lead-halide-based perovskite layers for efficient solar cells. Science 2017, 356, 1376-1379.

17. Correa-Baena, J.-P.; Abate, A.; Saliba, M.; Tress, W.; Jesper Jacobsson, T.; Grätzel, M.; Hagfeldt, A., The rapid evolution of highly efficient perovskite solar cells. Energy Environ. Sci. 2017, 10, 710-727.

18. Saliba, M.; Correa-Baena, J.-P.; Wolff, C. M.; Stolterfoht, M.; Phung, N.; Albrecht, S.; Neher, D.; Abate, A., How to Make over 20\% Efficient Perovskite Solar Cells in Regular (n-i-p) and Inverted (p-i-n) Architectures. Chem. Mater. 2018, 30, 4193-4201. 
19. Bishop, J. E.; Routledge, T. J.; Lidzey, D. G., Advances in Spray-Cast Perovskite Solar Cells. J. Phys. Chem. Lett. 2018, 9, 1977-1984.

20. Hwang, K.; Jung, Y.-S.; Heo, Y.-J.; Scholes, F. H.; Watkins, S. E.; Subbiah, J.; Jones, D. J.; Kim, D.-Y.; Vak, D., Toward Large Scale Roll-to-Roll Production of Fully Printed Perovskite Solar Cells. Adv. Mater. 2015, 27, 1241-1247.

21. Williams, S. T.; Rajagopal, A.; Chueh, C.-C.; Jen, A. K. Y., Current Challenges and Prospective Research for Upscaling Hybrid Perovskite Photovoltaics. J. Phys. Chem. Lett. 2016, 7 , 811-819.

22. Cai, M.; Wu, Y.; Chen, H.; Yang, X.; Qiang, Y.; Han, L., Cost-Performance Analysis of Perovskite Solar Modules. Adv. Sci. 2017, 4, 1600269.

23. Huang, F.; Li, M.; Siffalovic, P.; Cao, G.; Tian, J., From scalable solution fabrication of perovskite films towards commercialization of solar cells. Energy Environ. Sci. 2019, 12, 518-549.

24. Akkerman, Q. A.; Rainò, G.; Kovalenko, M. V.; Manna, L., Genesis, challenges and opportunities for colloidal lead halide perovskite nanocrystals. Nature Mater. 2018, 17, 394-405.

25. Wu, T.; Wang, Y.; Li, X.; Wu, Y.; Meng, X.; Cui, D.; Yang, X.; Han, L., Efficient Defect Passivation for Perovskite Solar Cells by Controlling the Electron Density Distribution of Donor- $\pi$ Acceptor Molecules. Adv. Energy Mater. 2019, 1803766.

26. Zuo, L.; Guo, H.; deQuilettes, D. W.; Jariwala, S.; De Marco, N.; Dong, S.; DeBlock, R.; Ginger, D. S.; Dunn, B.; Wang, M.; Yang, Y., Polymer-modified halide perovskite films for efficient and stable planar heterojunction solar cells. Science Adv. 2017, 3, e1700106.

27. Li, B.; Zhang, Y.; Fu, L.; Yu, T.; Zhou, S.; Zhang, L.; Yin, L., Surface passivation engineering strategy to fully-inorganic cubic $\mathrm{CsPbI} 3$ perovskites for high-performance solar cells. Nature Commun. 2018, 9, 1076.

28. Xue, Q.; Hu, Z.; Sun, C.; Chen, Z.; Huang, F.; Yip, H.-L.; Cao, Y., Metallohalide perovskite-polymer composite film for hybrid planar heterojunction solar cells. RSC Advances 2015, 5, 775-783. 
29. Saunders, B. R.; Vincent, B., Microgel particles as model colloids: theory, properties and applications. Adv. Coll. Intef. Sci. 1999, 80, 1-25.

30. Dokkhan, C.; Mokhtar, M. Z.; Chen, Q.; Saunders, B. R.; Hodson, N. W.; Hamilton, B., Using microgels to control the morphology and optoelectronic properties of hybrid organicinorganic perovskite films. Phys. Chem. Chem. Phys. 2018, 20, 27959-27969.

31. Ke, W.; Xiao, C.; Wang, C.; Saparov, B.; Duan, H.-S.; Zhao, D.; Xiao, Z.; Schulz, P.; Harvey, S. P.; Liao, W.; Meng, W.; Yu, Y.; Cimaroli, A. J.; Jiang, C.-S.; Zhu, K.; Al-Jassim, M.; Fang, G.; Mitzi, D. B.; Yan, Y., Employing Lead Thiocyanate Additive to Reduce the Hysteresis and Boost the Fill Factor of Planar Perovskite Solar Cells. Adv. Mater. 2016, 28, 5214-5221. 32. Hörantner, M. T.; Zhang, W.; Saliba, M.; Wojciechowski, K.; Snaith, H. J., Templated microstructural growth of perovskite thin films via colloidal monolayer lithography. Energy Environ. Sci. 2015, 8, 2041-2047.

33. You, P.; Liu, Z.; Tai, Q.; Liu, S.; Yan, F., Efficient Semitransparent Perovskite Solar Cells with Graphene Electrodes. Adv. Mater. 2015, 27, 3632-3638.

34. Guo, F.; Azimi, H.; Hou, Y.; Przybilla, T.; Hu, M.; Bronnbauer, C.; Langner, S.; Spiecker, E.; Forberich, K.; Brabec, C. J., High-performance semitransparent perovskite solar cells with solution-processed silver nanowires as top electrodes. Nanoscale 2015, 7, 1642-1649.

35. Eperon, G. E.; Burlakov, V. M.; Goriely, A.; Snaith, H. J., Neutral Color Semitransparent Microstructured Perovskite Solar Cells. ACS Nano 2014, 8, 591-598.

36. Lin, J.; Lai, M.; Dou, L.; Kley, C. S.; Chen, H.; Peng, F.; Sun, J.; Lu, D.; Hawks, S. A.; Xie, C.; Cui, F.; Alivisatos, A. P.; Limmer, D. T.; Yang, P., Thermochromic halide perovskite solar cells. Nature Mater. 2018, 17, 261-267.

37. Service, R. F., See-through solar cells could power offices. Science 2018, 360, 1386-1386.

38. Chen, K.-S.; Salinas, J.-F.; Yip, H.-L.; Huo, L.; Hou, J.; Jen, A. K. Y., Semi-transparent polymer solar cells with $6 \%$ PCE, $25 \%$ average visible transmittance and a color rendering index close to 100 for power generating window applications. Energy Environ. Sci. 2012, 5, 9551-9557. 
39. Xue, Q.; Bai, Y.; Liu, M.; Xia, R.; Hu, Z.; Chen, Z.; Jiang, X.-F.; Huang, F.; Yang, S.;

Matsuo, Y.; Yip, H.-L.; Cao, Y., Dual Interfacial Modifications Enable High Performance Semitransparent Perovskite Solar Cells with Large Open Circuit Voltage and Fill Factor. Adv. Energy Mater. 2017, 7, 1602333.

40. Zhang, S.; Lu, Y.; Lin, B.; Zhu, Y.; Zhang, K.; Yuan, N.-Y.; Ding, J.-N.; Fang, B., PVDFHFP additive for visible-light-semitransparent perovskite films yielding enhanced photovoltaic performance. Sol. Energy Mater. Sol. Cells 2017, 170, 178-186.

41. Chen, M.; Mokhtar, M. Z.; Whittaker, E.; Lian, Q.; Hamilton, B.; O'Brien, P.; Zhu, M.; Cui, Z.; Haque, S. A.; Saunders, B. R., Reducing hole transporter use and increasing perovskite solar cell stability with dual-role polystyrene microgel particles. Nanoscale 2017, 9, 10126-10137.

42. Xue, Q.; Xia, R.; Brabec, C. J.; Yip, H.-L., Recent advances in semi-transparent polymer and perovskite solar cells for power generating window applications. Energy Environ. Sci. 2018, 11, 1688-1709.

43. Cho, S.-P.; Na, S.-i.; Kim, S.-S., Efficient ITO-free semitransparent perovskite solar cells with metal transparent electrodes. Sol. Energy Mater. Sol. Cells 2019, 196, 1-8.

44. Ying, Z.; Chen, W.; Lin, Y.; He, Z.; Chen, T.; Zhu, Y.; Zhang, X.; Yang, X.; Djurišić, A. B.; He, Z., Supersmooth Ta2O5/Ag/Polyetherimide Film as the Rear Transparent Electrode for High Performance Semitransparent Perovskite Solar Cells. Adv. Opt. Mater. 2019, 7, 1801409.

45. Yang, B.; Wang, M.; Hu, X.; Zhou, T.; Zang, Z., Highly efficient semitransparent CsPbIBr2 perovskite solar cells via low-temperature processed In2S3 as electron-transport-layer. Nano Energy 2019, 57, 718-727.

46. Yuan, L.; Wang, Z.; Duan, R.; Huang, P.; Zhang, K.; Chen, Q.; Allam, N. K.; Zhou, Y.; Song, B.; Li, Y., Semi-transparent perovskite solar cells: unveiling the trade-off between transparency and efficiency. J. Mater. Chem. A 2018, 6, 19696-19702.

47. Zhou, Z.; Qiang, Z.; Sakamaki, T.; Takei, I.; Shang, R.; Nakamura, E., Organic/Inorganic Hybrid p-Type Semiconductor Doping Affords Hole Transporting Layer Free Thin-Film Perovskite 
Solar Cells with High Stability. ACS Appl. Mater. Interfaces 2019, 11, 22603-22611.

48. Islam, M. B.; Yanagida, M.; Shirai, Y.; Nabetani, Y.; Miyano, K., Highly stable semitransparent MAPbI3 perovskite solar cells with operational output for 4000 h. Sol. Energy Mater. Sol. Cells 2019, 195, 323-329.

49. Wang, Y.; Mahmoudi, T.; Yang, H.-Y.; Bhat, K. S.; Yoo, J.-Y.; Hahn, Y.-B., Fullyambient-processed mesoscopic semitransparent perovskite solar cells by islands-structure-MAPbI3xClx-NiO composite and Al2O3/NiO interface engineering. Nano Energy 2018, 49, 59-66.

50. Lee, J.-W.; Kim, H.-S.; Park, N.-G., Lewis Acid-Base Adduct Approach for High Efficiency Perovskite Solar Cells. Acc. Chem. Res. 2016, 49, 311-319.

51. Han, L.; Cong, S.; Yang, H.; Lou, Y.; Wang, H.; Huang, J.; Zhu, J.; Wu, Y.; Chen, Q.; Zhang, B.; Zhang, L.; Zou, G., Environmental-Friendly Urea Additive Induced Large Perovskite Grains for High Performance Inverted Solar Cells. Solar RRL 2018, 2, 1800054.

52. Ahn, N.; Son, D.-Y.; Jang, I.-H.; Kang, S. M.; Choi, M.; Park, N.-G., Highly Reproducible Perovskite Solar Cells with Average Efficiency of $18.3 \%$ and Best Efficiency of $19.7 \%$ Fabricated via Lewis Base Adduct of Lead(II) Iodide. J. Amer. Chem. Soc. 2015, 137, 8696-8699.

53. Cao, X.; Zhi, L.; Li, Y.; Fang, F.; Cui, X.; Yao, Y.; Ci, L.; Ding, K.; Wei, J., Control of the morphology of PbI2 films for efficient perovskite solar cells by strong Lewis base additives. $J$. Mater. Chem. C 2017, 5, 7458-7464.

54. Etgar, L.; Gao, P.; Xue, Z.; Peng, Q.; Chandiran, A. K.; Liu, B.; Nazeeruddin, M. K.; Grätzel, M., Mesoscopic CH3NH3PbI3/TiO2 Heterojunction Solar Cells. J. Amer. Chem. Soc. 2012, 134, 17396-17399.

55. Thaiboonrod, S.; Berkland, C.; Milani, A. H.; Ulijn, R.; Saunders, B. R., Poly(vinylamine) microgels: pH-responsive particles with high primary amine contents. Soft Matter 2013, 9, 39203930.

56. Li, B.; Li, M.; Fei, C.; Cao, G.; Tian, J., Colloidal engineering for monolayer CH3NH3PbI3 films toward high performance perovskite solar cells. J. Mater. Chem. A 2017, 5, 24168-24177. 
57. Tai, Q.; Yan, F., Emerging Semitransparent Solar Cells: Materials and Device Design. Adv. Mater. 2017, 29, 1700192.

58. Ke, J. C.-R.; Walton, A. S.; Lewis, D. J.; Tedstone, A.; O'Brien, P.; Thomas, A. G.; Flavell, W. R., In situ investigation of degradation at organometal halide perovskite surfaces by X-ray photoelectron spectroscopy at realistic water vapour pressure. Chem. Commun. 2017, 53, 52315234.

59. Ke, J. C.-R.; Lewis, D. J.; Walton, A. S.; Spencer, B. F.; O'Brien, P.; Thomas, A. G.;

Flavell, W. R., Ambient-Air-Stable Inorganic Cs2SnI6 Double Perovskite Thin Films via AerosolAssisted Chemical Vapour Deposition. J. Mater. Chem. A 2018, 6, 11205-11214.

60. Fairley, N., CasaXPS manual 2.3. 15. Acolyte Science: 2009.

61. Shirley, D. A., High-Resolution X-Ray Photoemission Spectrum of the Valence Bands of Gold. Phys. Rev. B 1972, 5, 4709-4714.

62. Schmidt, S.; Motschmann, H.; Hellweg, T.; von Klitzing, R., Thermoresponsive surfaces by spin-coating of PNIPAM-co-PAA microgels: A combined AFM and ellipsometry study. Polymer 2008, 49, 749-756.

63. Stoumpos, C. C.; Malliakas, C. D.; Kanatzidis, M. G., Semiconducting Tin and Lead Iodide Perovskites with Organic Cations: Phase Transitions, High Mobilities, and Near-Infrared Photoluminescent Properties. Inorg. Chem. 2013, 52, 9019-9038.

64. Bag, S.; Durstock, M. F., Efficient semi-transparent planar perovskite solar cells using a 'molecular glue'. Nano Energy 2016, 30, 542-548.

65. Marongiu, D.; Lai, S.; Sarritzu, V.; Pinna, E.; Mula, G.; Mercuri, M. L.; Saba, M.; Quochi, F.; Mura, A.; Bongiovanni, G., Bifacial Diffuse Absorptance of Semitransparent Microstructured Perovskite Solar Cells. ACS Appl. Mater. Interfaces 2019, 11, 10021-10027.

66. Chen, S.; Chen, B.; Gao, X.; Dong, B.; Hu, H.; Yan, K.; Wen, W.; Zou, D., Neutral-colored semitransparent solar cells based on pseudohalide ( $\mathrm{SCN}-$ )-doped perovskite. Sustainable Energy Fuels 2017, 1, 1034-1040. 
67. Park, Y. S.; Ito, Y.; Imanishi, Y., Permeation Control through Porous Membranes Immobilized with Thermosensitive Polymer. Langmuir 1998, 14, 910-914.

68. John, R.; Trommler, K.; Schreiter, K.; Siegel, C.; Simon, F.; Wagenfuhr, A.; Spange, S., Controlled synthesis of stable poly(vinyl formamide-co-vinyl amine)/silica hybrid particles by interfacial post-cross-linking reactions. BioResources 2017, 12, 8134-8159.

69. Seifert, S.; Höhne, S.; Simon, F.; Hanzelmann, C.; Winkler, R.; Schmidt, T.; Frenzel, R.; Uhlmann, P.; Spange, S., Adsorption of Poly(vinylformamide-co-vinylamine) Polymers (PVFA-coPVAm) on Copper. Langmuir 2012, 28, 14935-14943.

70. Voigt, I.; Simon, F.; Komber, H.; Jacobasch, H.-J.; Spange, S., Controlled synthesis of stable poly(vinyl formamide-co-vinyl amine)/silica hybrid particles by interfacial post-cross-linking reactions. Coll. Polym. Sci. 2000, 278, 48-56.

71. Calloni, A.; Abate, A.; Bussetti, G.; Berti, G.; Yivlialin, R.; Ciccacci, F.; Duo, L., Stability of organic cations in solution-processed $\mathrm{CH} 3 \mathrm{NH} 3 \mathrm{PbI} 3$ perovskites: formation of modified surface layers. J. Phys. Chem. C 2015, 119, 21329-21335.

72. De Bastiani, M.; D’Innocenzo, V.; Stranks, S. D.; Snaith, H. J.; Petrozza, A., Role of the crystallization substrate on the photoluminescence properties of organo-lead mixed halides perovskites. APL Mater. 2014, 2, 081509.

73. Zhang, Z.; Wang, M.; Ren, L.; Jin, K., Tunability of Band Gap and Photoluminescence in CH3NH3PbI3 Films by Anodized Aluminum Oxide Templates. Sci. Rep. 2017, 7, 1918.

74. Salado, M.; Jodlowski, A. D.; Roldan-Carmona, C.; de Miguel, G.; Kazim, S.; Nazeeruddin, M. K.; Ahmad, S., Surface passivation of perovskite layers using heterocyclic halides: Improved photovoltaic properties and intrinsic stability. Nano Energy 2018, 50, 220-228.

75. Ghosh, J.; Ghosh, R.; Giri, P. K., Mesoporous Si Nanowire Templated Controlled Fabrication of Organometal Halide Perovskite Nanoparticles with High Photoluminescence Quantum Yield for Light-Emitting Applications. ACS Appl. Nano Mater. 2018, 1, 1551-1562.

76. Tian, Y.; Merdasa, A.; Unger, E.; Abdellah, M.; Zheng, K.; McKibbin, S.; Mikkelsen, A.; 
Pullerits, T.; Yartsev, A.; Sundström, V.; Scheblykin, I. G., Enhanced Organo-Metal Halide Perovskite Photoluminescence from Nanosized Defect-Free Crystallites and Emitting Sites. J. Phys.

Chem. Lett. 2015, 6, 4171-4177. 